\title{
Basement membrane in health and disease- an enigma to histopathologist
}

\author{
Vijaykumar Biradar ${ }^{1, *}$, Namita Shrivastav ${ }^{2}$, Priya Shree ${ }^{3}$, Rakhee Sinha $^{4}$, Akhilanand Chaurasia ${ }^{5}$ \\ ${ }^{1}$ Reader, ${ }^{2-4}$ Senior Lecturer, ${ }^{5}$ Associate Professor, ${ }^{1-4}$ Dept. of Oral Pathology, Vananchal Dental College \& Hospital, Garhwa, \\ Jharkhand, ${ }^{5}$ Dept. of Oral Medicine \& Radiology, King's George Medical University, Lucknow, Uttar Pradesh, India
}

*Corresponding Author:

Email: drvijay06_biradar@yahoo.com

\begin{abstract}
Basemwnt membrane is known to play a role in the pathogenesis of inflammatory, tumor invasion, metastases and autoimmune diseases. A basement membrane (BM) is a thick sheet of extracellular matrix molecules, upon which epithelial cells attach and form a boundary between epithelium and the connective tissue. It also provides structural support for epithelial, mesothelial, and endothelial cells and surrounds adipocytes, muscles and Schwann cells. This literature review describes terminologies, histology, ultrastructure, molecular aspects, functions and histochemical studies of basement membrane in health and disease.
\end{abstract}

Keywords: Basement membrane, Extracellular matrix, Health, Disease.

\section{Introduction}

Basement membrane is composed of thin, sheetlike structures that form flexible boundaries between tissue compartments. Basement membrane can be defined as an extensive interface between connective tissue and the various tissues that it supports and nourishes (namely epithelial, nervous and muscle tissues etc.) and is characterized by the presence of a thin layer of specialized intercellular matrix. This extracellular layer is so called because the first site where it was noticed was immediately beneath the basal surface of epithelial cell membranes. ${ }^{1,2}$

\section{Terminologies}

Basement membrane is an old established histological term. When it was viewed under electron microscope (EM), it reveals an electron-dense layer that follows the contours of the basal cell surface and is separated from it by an electron-lucid layer. This electron-dense layer was first given the name 'Basal Lamina.'

However, subsequent indiscriminate use of the terms 'basement membrane' and 'basal lamina' caused confusion because these two terms were initially thought to denote the same structure observed at the light and electron microscope levels, respectively.

Now, it is clear that electron-dense layer seen in the EM (formerly known as basal lamina) represents only a part of the basement membrane and is now called as 'lamina densa.' The convention has been to call the lamina rara on the connective tissue side, the lamina rara interna and the lamina rara on the cellular side, the lamina rara externa. However, even this nomenclature presents some difficulties when it comes to describing the other tissues (like glomerular basement membrane of the kidneys).

As a result a third terminology has been introduced to overcome the problem of deciding which side is external and which side is internal. Hence, lamina rara externa is now known as lamina lucida, and lamina rara interna is known as lamina fibroreticularis. ${ }^{1,3}$

According to some authors, basal lamina comprises both lamina lucida and lamina densa, and basement membrane comprises basal lamina and lamina fibroreticularis. Thus basement membrane is made of:

1. Basal lamina:

a. Lamina lucida

b. Lamina densa

2. Lamina fibroreticularis $s^{4-7}$

Sometimes, the basal lamina is used synonymously with basement membrane. Those who insist on using basement membrane as a term in EM should make it clear whether they are using it as a synonym for basal lamina or in its wider context. ${ }^{3}$

The basement membrane is a composite structure that includes not only the lamina densa but also a less distinct electron-lucent layer on either side of lamina densa that is referred to as "lamina rara.

\section{Structure and molecular aspects of basement membrane}

The term "basement membrane" actually refers to the structure seen using light microscopy. ${ }^{8,9}$ With conventional light microscopy, one cannot appreciate the complexity of the basement membrane's structure. With routine staining (Fig. 1), the basement membrane appears to be little more than a barely perceptible thin undulating line beneath the epidermis ${ }^{10}$. Standard hematoxylin and eosin (H\&E) stains impart a pink color to collagen and dermal tissues and do not routinely stain the basement membrane adequately. Special stains such as (PAS) Periodic acid-schiff stain (Fig. 2) that imparts a reddish purple color to glycogen, mucopolysaccharides, and mucin, are used to identify the basement membrane more clearly. ${ }^{9,11}$ 


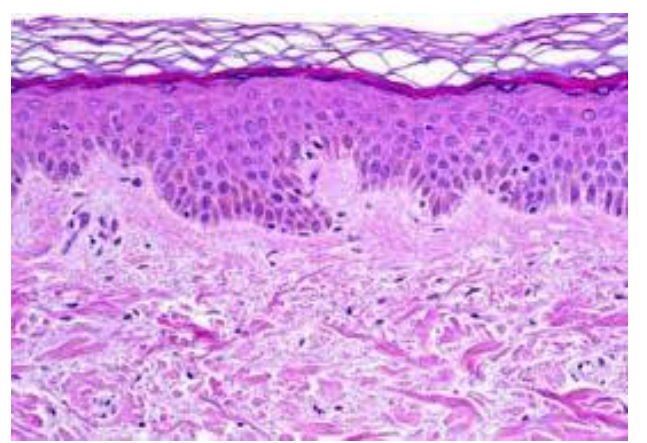

Fig. 1: Hematoxylin and eosin stain of normal skin

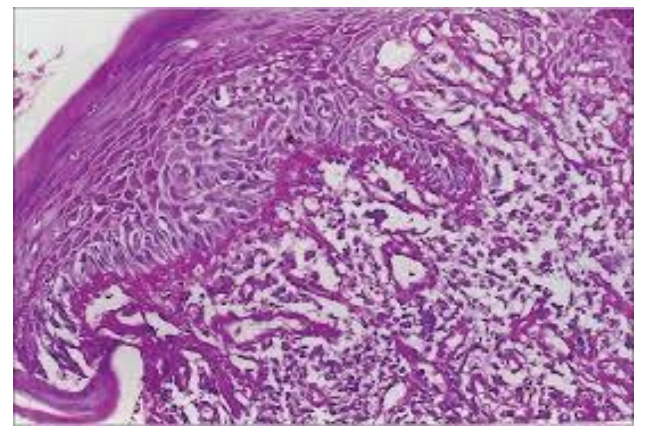

Fig. 2: PAS stain of basement membrane

Based on the electron microscopic appearance of the basement membrane zone, this zone is divided into four distinct layers (Fig. 3). These four distinct layers are the: (1) the basal keratinocyte layer; (2) the lamina lucida; (3) the lamina densa; and (4) the sublamina densa (superficial papillary dermis). Collectively, these layers make up the "basement membrane zone"

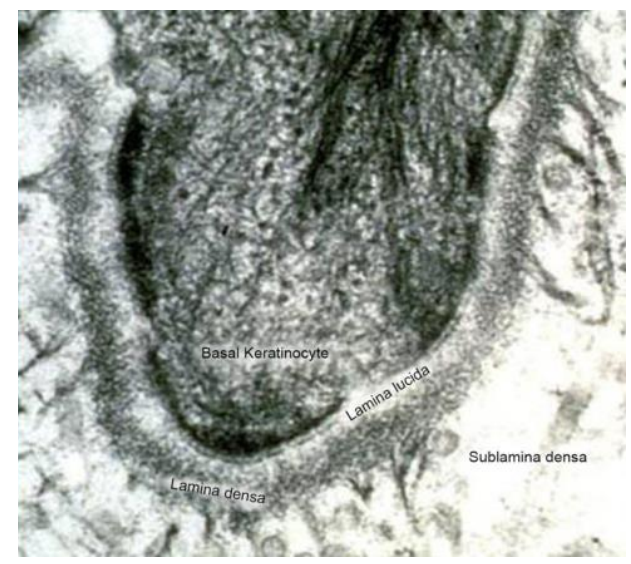

Fig. 3: Four layers of the basement membrane zone. (1) The basal keratinocyte layer; (2) the lamina lucida; (3) the lamina densa; and (4) the sublamina densa (lamina reticularis)

Principal molecular constituents of the junction between epithelium and connective tissue:

1. Hemidesmosomes

2. Lamina lucida

3. Lamina densa

4. Lamina fibroreticularis ${ }^{3}$

\section{Hemidesmosomes}

Hemidesmosome is a specialized junction and classified as cell-matrix junction. ${ }^{12}$ As the name implies, they resemble exactly one-half of a desmosome consisting of a dense cytoplasmic plaque immediately adjacent to plasma membrane with filaments radiating into the cytoplasm. ${ }^{3}$

Hemidesmosomes link the cell to basement membrane and through additional extracellular molecules to the rest of the extracellular matrix. On molecular level, hemidesmosome consist of three components: cytoskeletal filament, cytoplasmic adapter proteins and transmembrane adhesive protein (Integrin $\left.\alpha_{6} \beta_{4}\right)$ Fig. 4

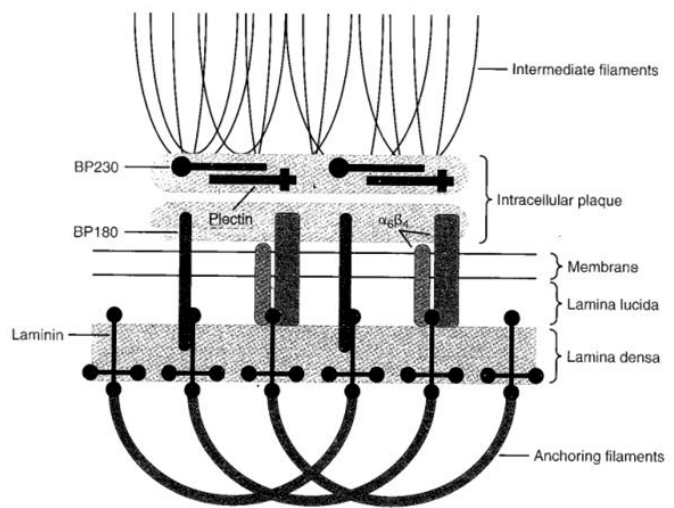

Fig. 4: Diagrammatic illustration of hemidesmosome

\section{Lamina Lucida}

It is an electron-lucent layer of thickness $10 \mathrm{~nm}$ to $50 \mathrm{~nm}$ lying immediately beneath the basal cell membranes of the epithelial cells. Lamina lucida is made of glycoproteins laminin, bullous pemphigoid antigen 180 (BP180) and basement membrane glycoprotein. ${ }^{4}$ On molecular level,lamina lucida consists of laminin and entactin. Laminin is the most abundant glycoprotein found in basement membrane. It consists of three distinct elongated polypeptide chains $\left(\mathrm{A}, \mathrm{B}_{1}\right.$ and $\left.\mathrm{B}_{2}\right)$ linked together to form an elongated cruciform shape. ${ }^{7}$ Entactin, also known as nidogen, is a dumbbell-shaped sulfated glycoprotein which binds laminin near its center and interacts with type IV collagen, bridging the two, and is a major cell attachment factor. ${ }^{7,13}$

\section{Lamina Densa}

It is an electron-dense layer of about $50 \mathrm{~nm}$ thickness which runs parallel to the basal cell membranes of epithelial cells and is separated from them by lamina lucida. Lamina densa consists of type IV collagen, heparan sulphate, type VII collagen, fibronectin and type $\mathrm{V}$ collagen ${ }^{5}$. 


\section{Lamina Fibroreticularis}

It is an ill-defined electron-lucent layer which is seen on connective tissue side of lamina densa and is variable in appearance. It is called so because; it typically lies in intimate association with reticular fibers of underlying connective tissue and consists of type III collagen. ${ }^{1,4}$

\section{Basement membrane in other tissues Tooth bud}

The outer enamel epithelium is separated from the dental sac by a basement membrane. Similarly the inner enamel epithelium is separated from the dental papilla by a basement membrane from which a mass of fine aperiodic fibrils extend into an acellular zone. These fibrils correspond to the lamina fibroreticularis of the basement membrane and there the first secreted enamel matrix proteins accumulate. These first enamel proteins play a role in the epithelial-mesenchymal signaling that leads to the terminal differentiation of odontoblasts. ${ }^{14}$ The basement membrane that separates enamel organ from dental papilla, just prior to dentin formation, is called as 'membrana preformativa.' 15

\section{Hertwig's epithelial root sheath (HERS)}

Unlike coronal dentinogenesis, where the firstformed collagen of mantle dentin is deposited against and at right angles to the basement membrane, the first formed collagen of root mantle dentin is deposited parallel to the basement membrane of the root sheath. Then Hertwig's epithelial root sheath disintegrates. ${ }^{4}$ The first changes in the root sheath are found in the basement membrane, which becomes indistinct and loses its continuity. ${ }^{16}$

\section{Cell rests of Malassez}

Hertwig's epithelial root sheath fragments to form a number of discrete clusters of epithelial cells called cell rests of Malassez, which are separated from the surrounding connective tissue by a basement membrane. ${ }^{16}$

\section{Reduced dental epithelium}

Before beginning eruptive movements, the crown of the tooth is covered by a double layer of epithelial cells called reduced dental epithelium. Those cells in contact with enamel are the ameloblasts which having completed their formative function develop hemidesmosomes, secrete a basal lamina and become firmly attached to the enamel surface. ${ }^{5}$

\section{Junctional epithelium (Attachment epithelium)}

Junctional epithelium is attached to the tooth surface by means of an internal basal lamina and to the gingival connective tissue by an external basal lamina. The junctional epithelium attaches to afibrillar cementum present on the coronal side (usually restricted to an area within $1 \mathrm{~mm}$ of CEJ) and to root cementum in a similar manner. ${ }^{17}$. Epithelial attachment is the ultrastructural attachment of the junctional epithelium to the tooth which consists of internal basal lamina and hemidesmosomes attached to it. ${ }^{15}$

\section{Salivary gland acini and salivary gland ducts}

The basement membrane is continuous around the salivary gland acini and the ducts. It forms complex tubular scaffolding within which the epithelial cells are arranged and it probably influences the maintainance of normal glandular architecture. ${ }^{5}$ Myoepithelial cells are interposed between the basement membrane and overlying epithelial cells of salivary gland acini and ducts. In basement membrane of striated ducts there are $\mathrm{Ca}^{++}$-ATPase and $\mathrm{Na}^{+}-\mathrm{K}^{+}$-ATPase pumps for ion transport function. ${ }^{16}$

\section{Blood vessels}

In blood vessels basement membrane underlie endothelial cells, encasing associated pericytes, and also surround individual smooth muscle cells in veins and arteries. In contrast to blood vessels, lymph vessels lack pericytes and do not possess a basement membrane. ${ }^{18}$

\section{Functions of basement membrane}

1. They provide adhesion on one side to epithelial (or parenchymal) cells; and on the other side to connective tissue (mainly collagen fibers). ${ }^{6}$

2. Basement membranes are freely permeable to substances of low molecular weight but impede the passage of macromolecules. Thus it acts as a dynamic sieve to control the passage of molecules between the epithelium and connective tissue and act as barrier to cell migration. ${ }^{5}$

3. Basement membrane plays a significant role in healing of wounds. It appears to be the main structural component necessary for organized regeneration, forming a 'scaffold' for the replicating parenchymal cells. When basement membrane is disrupted, cells may proliferate in a haphazard fashion and produce disorganized masses of cells bearing no resemblance to the original arrangement. Alternatively, scarring may ensue. ${ }^{19}$

4. After crush injury to peripheral nerves, persistent basal laminae help to form endoneural tubes that guide growing axons back to the periphery. ${ }^{3}$

5. The basement membrane is extremely resistant to injury and may remain as an effective barrier to the escape of blood cells after the endothelium has been destroyed. ${ }^{20}$

6. Basement membrane has important signaling functions in epithelial-mesenchymal interactions which are essential for epithelial differentiation and migration during morphogenesis as well as mesenchymal differentiation to some extent. These signaling functions are also essential for 
development and maintainance of cell polarity. These effects may depend on the filtration properties of basement membrane allowing chemical mediators to pass between the tissues in the correct quantities. Some proteoglycans in basement membrane can also bind growth factors such as, TGF- $\beta$ (transforming growth factor- $\beta$ ), modulating their effect on cells.

Tissue culture experiments have established that the differentiation of odontoblasts from the undifferentiated ectomesenchyme of the dental papilla is initiated by an organizing influence from the cells of the inner dental epithelium. In the absence of epithelial cells no dentin develops.

The epithelial cells of inner dental epithelium are inductive and have been shown to express and secrete several growth factors (transforming growth factor- $\beta 1$ [TGF- $\beta 1$ ], BMP-2 and insulinlike growth factor [IGF]) have been identified, which bind to the heparan sulphate in basement membrane, thereby transferring inductive ability to this structure. The ectomesenchymal cells of the dental papilla assume competence only after a set number of cell divisions, after which they presumably express the appropriate cell surface receptors able to capture the growth factors. ${ }^{14,21}$.

\section{Demonstration of basement membrane by histochemistry \\ Periodic acid- Schiff staining (PAS) \\ Basement membrane contains neutral} mucopolysaccharides (glycosaminoglycans). Hence it appears bright magenta colored in PAS staining. In PAS technique, tissue sections are exposed to Periodic acid which forms aldehydes from polysaccharides by breaking the carbon bonds (C-C) of structures present in the form of adjacent 1:2 glycol groups $(\mathrm{CHOH}-$ $\mathrm{CHOH}$ ). Periodic acid is the oxidant of choice, as it does not over-oxidize the formed aldehydes to carboxyl $(\mathrm{COOH})$. The tissue sections are then treated with the Schiff reagent which colors the sites of aldehyde production magenta. Collagenous fibers in general are colored only faintly by the PAS technique, whereas reticular fibers are strongly positive. This presumably is due to the presence of sugars intimately associated with the reticular fibers. ${ }^{22,23}$

\section{Methenamine silver (Jones) technique}

In this technique, basement membrane appears as a black line. The tissue sections are first treated with oxidizing agent chromic acid which produces aldehydes from glycogen present in basement membrane. These aldehydes reduce methenamine silver solution causing blackening of glycogen. ${ }^{22}$

\section{Immunofluorescent technique}

Immunofluorescent technique can detect chemically specific materials, which is achieved by the use of specific antibody. This antibody is irreversibly attached to the fluorescent marker. Thus the combination of fluorescein-conjugated specific antibody with its own particular antigen is visually detectable.

\section{Basement membrane in diseases}

Some of the oral diseases in which basement membrane changes are seen and are categorized as follows:

\section{Mucocutaneous Diseases}
A. Noninfectious erythematous, papular diseases
i. Lichen planus

B. Noninfectious vesiculo- bullous diseases
i. Bullous pemphigoid
ii. Cicatricial pemphigoid
iii. Erythema multiforme
iv. Dermatitis herpetiformis
v. Linear IgA disease
vi. Graft-versus-host disease
vii. Paraneoplastic pemphigus
viii. Herpes gestationis

C. Congenital (genodermatoses)

i. Epidermolysis bullosa

D. Connective tissue disease

i. Lupus erythematosus

E. Metabolic diseases
i. Hyalinosis cutis et mucosae
ii. Porphyria

\section{Neoplastic Diseases}

A. Odontogenic tumors

i. Adenomatoid odontogenic tumor

ii. Calcifying epithelial odontogenic tumor

B. B.Salivary gland neoplasms

C. Epithelial malignancies

i. Squamous cell carcinoma

ii. Verrucous carcinoma

D. Vascular neoplasms

i. Hemangiopericytoma

ii. Angiosarcoma

\section{Miscellaneous}

i. Inflammation

ii. Chronic desquamative gingivitis

iii. Diabetes mellitus

In lichen planus, there is liquefaction degeneration of the basal cell layer, ${ }^{1}$ the cicatricial pemphigoid shows the detachment of basement membrane from the underlying connective tissue, ${ }^{2}$ in bullous pemphigoid the basement membrane shows interruption in continuity. In erythema multiforme basement membrane at some instances is destroyed, it may be intact at the floor of bulla. ${ }^{15}$ Similarly in dermatitis herpetiformis, the subepithelial vesicle forms with destruction of basement membrane. ${ }^{2}$ In linear IgA 
disease only IgA deposition occur at basement membrane zone in a linear pattern in immunofluorescent study and histologically separation of the basement membrane is seen, ${ }^{15}$ in epidermolysis bullosa: Epidermolysis Bullosa Simplex PAS-positive basement membrane remains on dermal side of separation, junctional epidermolysis bullosa PASpositive basement membrane zone usually remain attached to dermis. Dystrophic epidermolysis bullosa dominant shows irregular PAS-positive basement membrane. Dystrophic epidermolysis bullosa recessive shows fragments of basement membrane adhering to the dermis. ${ }^{2}$ Lupus erythematosis shows the basement membrane zone may be fragmented and even sometimes absence of basement membrane. ${ }^{2}$ The Hyalinosis cutis et mucosae (lipoid proteinosis) have disruption or reduplication of basement membrane. ${ }^{2}$ The adenomatoid odontogenic tumor represent the reduplicated basement membrane. ${ }^{16}$ Calcifying epithelial odontogenic tumor shows degeneration of type IV collagen associated with basement membrane. ${ }^{3}$ Salivary gland neoplasms such as pleomorphic adenoma and adenoid cystic carcinoma shows discrete basal lamina lined. ${ }^{5}$ Basement membrane play an important role in differentiating carcinoma in situ to squamous cell carcinoma, in carcinoma in situ there is intact but indistinct basement membrane where as there is destruction of basement membrane and frank invasion of malignant epithelial cells in underlying connective tissue in squamous cell carcinoma. ${ }^{6}$ In hemangiopericytoma the tumor cells are seen to be located peripheral to the periendothelial basement membrane which is positive for silver stain. ${ }^{4}$ In angiosarcoma silver stain positive basement membrane is seen peripheral to the tumor cells ${ }^{4}$.During inflammation there is contraction, retraction or direct injury to endothelial cell along with release of various types of chemical mediators causing destruction of basement membrane. ${ }^{7}$ In chronic desquamative gingivitis(bullous type)thinning or absence of basement membrane is seen. ${ }^{12}$ In Diabetes mellitus diffuse thickening of basement membrane of blood vessels seen. ${ }^{6}$

\section{Conclusion}

Basement membranes are extracellular matrices composed mainly of type IV collagen; glycoproteins laminin, fibronectin; and proteoglycan heparan sulphate. They support parenchymal cells, act as semipermeable membranes to control passage of molecules and play important roles in regeneration and epithelial-mesenchymal interactions during embryogenesis which is essential for epithelial differentiation and migration.

Alterations in basement membrane such as thickening break in continuity, partial or complete destruction etc. are associated with various diseases and the histopathologist should be alert to look into the basement membrane changes in reporting the diagnosis of these diseases.

\section{References}

1. David H. Cormack. Ham's Histology, $9^{\text {th }}$ edition, J. B. Lipppincott Company, Philadelphia 1987. p: 165-8.

2. K. Heikinheimo, T. salo. Expression of basement membrane type IV collagen and type IV collagenases (MMP-2 and MMP-9) in human teeth. J Dent Res 1995:74(5):1226-34.

3. Cohen Bertram, Kramer Ivor R. H. Scientific Foundations of Dentistry, $1^{\text {st }}$ edition, William Heinemann Medical Books Ltd. London-1976. p: 68-69.

4. Christopher A. Squier, Mchael W. Finkelstein. Oral Mucosa. In Antonio Nanci. Ten Cate's Oral Histology Development, Structure and Function. $6^{\text {th }}$ edition, Mosby an Imprint of Elsevier, St. Louis, Missouri 63146- 003. Reprinted 2005.

5. R. Ten Cate. Oral Histology Development, Structure and Function, $5^{\text {th }}$ edition, Harcourt Asia Pte Ltd, Singapore 238884-1998. First printed in India 1999. p: 51-67, 97-9, 202-47.

6. Inderbir Singh. Textbook of Human Histology, $4^{\text {th }}$ edition, Jaypee Brothers Medical Publishers (P) Ltd., New Delhi 2002. Reprint-2005. p: 49.

7. J. H. Campbell, V. P. Terranova. Laminin: molecular organization and biological function. J Oral Pathol 1988:17:309-23.

8. Murphy G. Lever's histopathology of the skin. 8th ed. Philadelphia: Lippincott-Raven 1997.

9. Denduchis B, Kefalides NA, Bezkorovainy A. The chemistry of sheep anterior lens capsule. Arch Biochem Biophys 1970;138(2):582-9.

10. Kanitakis J. Anatomy, histology and immunohistochemistry of normal human skin. Eur J Dermatol 2002;12(4):390-400.

11. Briggaman RA, Wheeler CE. The epidermal-dermal junction. J Invest Dermatol. 1975;65(1):71-84.

12. Arthur R. Hand, A. Richard Ten Cate. Cytoskeleton, Junctions, and, Fibroblasts. In Antonio Nanci. Ten Cate's Oral Histology Development, Structure and Function. $6^{\text {th }}$ edition, Mosby An Imprint of Elsevier, St. Louis, Missouri 63146- 2003. Reprinted 2005.

13. P.D. Yurchenco, J.C. Schittny. Molecular architecture of basement membranes. The FASEB J 1990:4,1577-90.

14. Richard Ten Cate, Paul T. Sharpe, Stephane Roy, Antonio Nanci. Development of the tooth and its supporting tissues. In Antonio Nanci. Ten Cate's Oral Histology Development, Structure and Function. $6^{\text {th }}$ edition, Mosby An Imprint of Elsevier, St. Louis, Missouri 63146- 2003. Reprinted 2005.

15. Edited by- S. N. Bhaskar. Orban's Oral Histology and Embryology, $10^{\text {th }}$ edition, First Indian edition, CBS Publisher and Distributor, Delhi1990. p: 35-317.

16. Edited By I. A. Mjör, O. Fejerskov. Human Oral Embryology and Histology, $1^{\text {st }}$ edition, $1^{\text {st }}$ printing, Munskgaard, Copenhagen-1986. p: 168, 221-3, 249-65.

17. Joseph P. Fiorellini, David M. Kim, Satoshi O. Ishikawa. The Gingiva. In Michael G. Newman, Henry H. Takei, Perry R. Klokkevold. Editor- Fermina A. Carranza. Carranza's Clinical Periodontology, $10^{\text {th }}$ edition, Saunders an Imprint of Elsevier, St. Louis, Missouri-2006. First printed in India 2007.

18. Walter F. Lever, Gundula Schaumburg-Lever. Histopathology of The Skin, $6^{\text {th }}$ edition, J. B. Lippincott Company, Philadelphia 1983. p: 34, 113-20, 445-9, 635-42.

19. Ramzi S. Cotran, Vinay Kumar, Stanley L. Robbins. Robins Pathologic Basis of Disease, $4^{\text {th }}$ edition, W. B. Saunders Company, Harcourt Brace Jovanovich, Inc, Philadelphia 1989. p: 72, 255-60, 1000-4. 
20. J. V. Hurley. Acute Inflammation, Churchill Livingstone, Longman Group Ltd., Edinburgh and London 1972. p: 31, 80.

21. J. W. Rippin. Edited By Christopher L. B. Lavelle. Applied Physiology of the Mouth, $1^{\text {st }}$ edition, Bristol John Wright and Sons Ltd.1975. p: 6-7.

22. R.A. B. Durry, E. A. Wallington. Carleton's Histological Techniques, $5^{\text {th }}$ edition, Oxford University Press 1980. p: 237.

23. Thomas S. Lesson, Ronald Lesson. Histology, $4^{\text {th }}$ edition, W. B. Saunders Company, Philadelphia/London/Toronto and Holt-Saunders, Japan Ltd./Tokyo-1981. p: 117. 